\title{
The Activity of Infective Endocarditis Was Correlated to the Procalcitonin Value
}

\author{
Fumitsugu Yoshikawa ${ }^{\mathrm{a}}$, Kazunao Haba ${ }^{\mathrm{a}}$, Tetsu Nakajima ${ }^{\mathrm{a}}$, Setsuo Kumazaki ${ }^{\mathrm{a}}$, Masaharu Hanada ${ }^{\mathrm{a}}$, \\ Kazuo Hirata ${ }^{\mathrm{a}}$, Ryuichi Aikawa ${ }^{\mathrm{a}, \mathrm{b}}$
}

\begin{abstract}
An 89-year-old woman was introduced and followed up at our hospital office after being treated by antibiotics including ampicillin (ABPC) against infective endocarditis (IE) in another hospital. Although her CRP was in the negative range at first, her procalcitonin (PCT) was slightly positive in her blood exam. Then, she had a recurrence with high fever 1 week after the ABPC medication was stopped, and the patient was admitted into our hospital. Immediately, we started to administrate some antibiotics based on a result of blood culture of bacteria. Finally, both the CRP and the PCT showed negative 28 days after the beginning of the treatment. The feverish state was not observed even after the medication was finished. In the second case, a 77-yearold man with high fever was admitted in our hospital and diagnosed with IE by transesophageal echocardiography. The antibiotic therapy was started and the fever was gradually declined. The only CRP became negative 14 days after the beginning of the medication. Finally both the CRP and the PCT was completely negative at 21 days. It is possible that the PCT should be an appropriate marker for the treatment of IE compared to CRP.
\end{abstract}

Keywords: Infective endocarditis; Procalcitonin; Antibiotic therapy

\section{Introduction}

Infective endocarditis (IE) is an infection of the heart valves or the endocardium. They perform antibiotic therapy for the treatment of IE around 4 - 6 weeks as shown in the guidelines $[1,2]$. However, there does not show the critical point of stopping the antibiotic therapy. Procalcitonin (PCT) is an innovative and highly specific marker for the diagnosis of clinically relevant bacterial infections and sepsis $[3,4]$. We experienced that PCT was more useful and sensitive to IE treatment com-

Manuscript accepted for publication March 12, 2015

aKuwana City Medical Center, 1-32-1, Chu-o, Kuwana, Mie 511-0068, Japan ${ }^{\mathrm{b} C}$ Corresponding Author: Ryuichi Aikawa, Kuwana City Medical Center, 1-32-

1, Chu-o, Kuwana, Mie 511-0068, Japan. Email: ryuichi_aikawa@yahoo.co.jp

doi: http://dx.doi.org/10.14740/jmc2091w pared to standard clinical inflammation marker, CRP.

\section{Case Report}

In the first case, an 89-year-old woman was diagnosed with mitral valve IE due to methicillin-sensitive Staphylococcus aureus (MSSA) and treated with antibiotics in another hospital. After her discharge of the hospital, she was introduced to our hospital at 21 days prior to this hospitalization. At that time, her CRP was in the negative range $(<0.3 \mathrm{mg} / \mathrm{dL})$, but her procalcitonin $(\mathrm{PCT})$ was slightly high $(0.06 \mathrm{ng} / \mathrm{mL})$ in her blood exam (Fig. 1). Because of the mild elevation of PCT, the medication of ampicillin tablet (AMPC), which was prescribed from the previous hospital, was continued for 2 weeks in our hospital, and the PCT was still remained mild positive $(0.06 \mathrm{ng} / \mathrm{mL})$ in Figure 1. We decided to stop the medication by the reason why the PCT was stable and the CRP was almost negative. However, the woman had a high fever again 1 week after stopped the AMPC medication, and then, the patient was

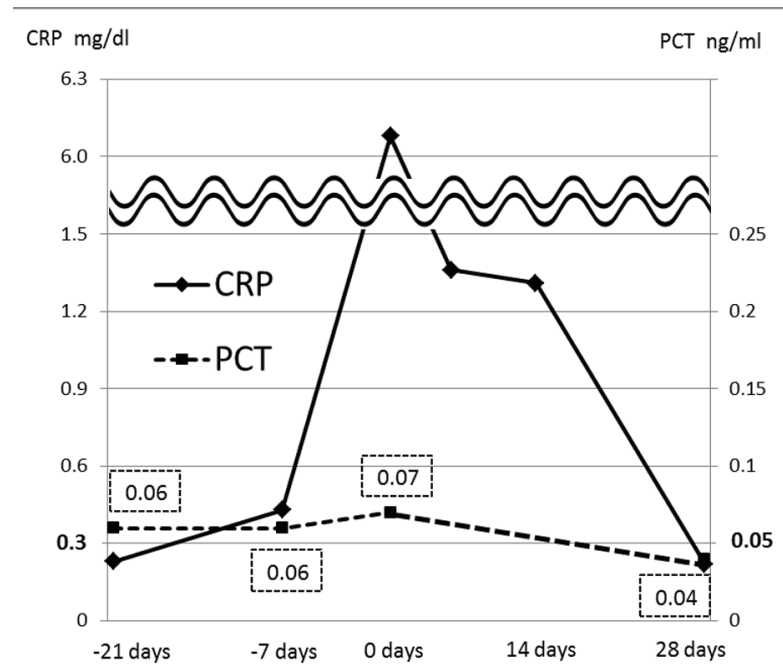

Figure 1. Time course of procalcitonin (dotted line) and CRP (solid line) values in the first patient. The standard value of procalcitonin is less than $0.05 \mathrm{ng} / \mathrm{mL}$ and the CRP is less than $0.3 \mathrm{mg} / \mathrm{dL}$. The day 0 shows that the patient was entered into our hospital. The rectangle of dotted line shows a procalcitonin value. 


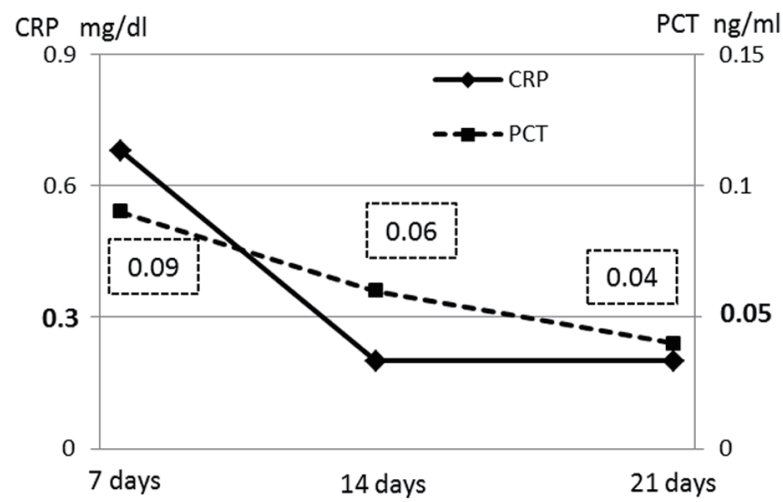

Figure 2. Time course of procalcitonin (dotted line) and CRP (solid line) values in the second patient. The rectangle of dotted line shows a procalcitonin value at 7,14 and 21 days after entrance of our hospital.

entered into our hospital. At that time, both CRP $(6.1 \mathrm{mg} / \mathrm{dL})$ and PCT $(0.07 \mathrm{ng} / \mathrm{mL})$ were elevated as shown in Figure 1. Immediately, we began to administrate some antibiotics of cefazolin (CEZ), tosulfoxacin (TFLX) and AMPC based on data of her blood culture for drug sensitiveness against MSSA as same as previously. Finally, both the CRP $(<0.3 \mathrm{mg} / \mathrm{dL})$ and the PCT $(<0.05 \mathrm{ng} / \mathrm{dL})$ showed completely negative 28 days after the beginning of the treatment in Figure 1. The feverish state was not observed even after all antibiotics were finished.

In the second case, a 77-year-old man with high fever was admitted in our hospital and diagnosed with tricuspid valve IE by transesophageal echocardiography. The combination antibiotic therapy of ceftriaxone (CTRX) and amikacin (AMK) was started against MSSA and the fever was gradually declined. Due to blood tests, although the CRP became negative $(<0.3$ $\mathrm{mg} / \mathrm{dL})$, the PCT was still slightly high $(0.06 \mathrm{ng} / \mathrm{mL}) 14$ days after the beginning of the medication in Figure 2. Finally both the CRP and the PCT became perfectly negative at 21 days in Figure 2. So, we finished administrating all antibiotics and the general condition of the patient was kept stable without any infectious signs.

\section{Discussion}

It has been shown to continue to use antibiotics for 4 - 6 weeks for the treatment of IE in the guideline of the American Heart Association and the Japanese Circulation Society $[1,2]$. However, there has not demonstrated the appropriate marker to finish the antibiotic therapy. We tried to measure PCT with CRP to evaluate the activity of IE. In the first case, the patient had a recurrence of IE after stopping antibiotic therapy in the condition with positive PCT and negative CRP. In addition, neither of the patients had a recurrence if PCT became completely negative even without antibiotic medicine. As demonstrated in Table $1[3,4]$, there exists a clinical difference between 0.04
Table 1. Procalcitonin Standard Value

\begin{tabular}{ll}
\hline PCT $(\mathbf{n g} / \mathbf{m L})$ & \\
\hline$<0.05$ & Healthy \\
$<0.5$ & Local infections \\
$0.5-2.0$ & Systemic infections (sepsis) \\
$2.0-10$ & Severe sepsis \\
$>10$ & Septic shock \\
\hline
\end{tabular}

and 0.05 in PCT values. In the present IE cases, we observed the same tendency that the infection was well controlled when the PCT was decreased less than 0.05. Moreover, the PCT of both patients was switched to negative following that the CRP became negative at first. Accordingly, PCT may be useful to indicate slight-local infection compared to CRP as an infectious marker. PCT may also be an appropriate marker to finish antibiotic therapy for IE. Further studies with many IE patients are required to establish it.

\section{Disclosures}

We demonstrated this report in the No. 144th Tokai Regional Meeting of the Japanese Circulation Society. The authors report no financial relationships or conflicts of interest regarding the content herein.

\section{References}

1. Baddour LM, Wilson WR, Bayer AS, Fowler VG, Jr., Bolger AF, Levison ME, Ferrieri P, et al. Infective endocarditis: diagnosis, antimicrobial therapy, and management of complications: a statement for healthcare professionals from the Committee on Rheumatic Fever, Endocarditis, and Kawasaki Disease, Council on Cardiovascular Disease in the Young, and the Councils on Clinical Cardiology, Stroke, and Cardiovascular Surgery and Anesthesia, American Heart Association: endorsed by the Infectious Diseases Society of America. Circulation. 2005;111(23):e394-434.

2. Councils on Japanese Circulation Society. Circulation Journal. 2003; 67(Suppl IV).

3. Harbarth S, Holeckova K, Froidevaux C, Pittet D, Ricou B, Grau GE, Vadas L, et al. Diagnostic value of procalcitonin, interleukin-6, and interleukin-8 in critically ill patients admitted with suspected sepsis. Am J Respir Crit Care Med. 2001;164(3):396-402.

4. Morgenthaler NG, Struck J, Fischer-Schulz C, SeidelMueller E, Beier W, Bergmann A. Detection of procalcitonin (PCT) in healthy controls and patients with local infection by a sensitive ILMA. Clin Lab. 2002;48(56):263-270. 